\title{
Transient Negative-sequence Component Calculation for Large Generator Based on Wavelet Transform
}

\author{
Wu Guo ${ }^{1}$, Bao-jun $\mathrm{Ge}^{1}$, Jian Guo ${ }^{2}$ and Yun-peng Gao ${ }^{1}$ \\ 1. Collage of Electrical and Electronic Engineering \\ Harbin University of Science and Technology, Harbin, China, 150080 \\ 2. Collage of Architecture and Civil Engineering \\ Qiqihar University, Qiqihar, China, 161006 \\ E-mail: guowuhaligong@126.com
}

\begin{abstract}
The current in frequency domain can not be analyzed at the same time because of the limitations of the Fourier transform algorithm. Hence, the wavelet transform method is used to analyze the short circuit transient current and calculate the negative-sequence component in this paper. Then, the non-periodic component and periodic component fundamental wave of the transient current are obtained, and the high harmonic components and decreased periodic component are removed. The non-periodic component is seriously considered in the transient negative-sequence component calculation. The calculation results indicate that the transient negative-sequence component contains two parts, the equivalent negative-sequence component of nonperiodic component and the negative-sequence component of negative-sequence current. The world's first AP1000 third generation 1250 MVA nuclear half-speed (4-pole) turbogenerator is adopted as the calculation model. The transient parameters of the large generator are calculated on the principle of transformed current waveform in the internal short circuit fault condition. Furthermore, the transient negative-sequence component of the large-capacity generator is also calculated and the negative-sequence ability is deeply discussed in this work, which provides a theoretical basis for the large generators' protection and design.
\end{abstract}

Keywords: negative-sequence component, transient current analysis, large generator, wavelet transform, internal short circuit fault

\section{Introduction}

Generator simulation based on the finite element method is one of the most simple and effective solutions to reflect the electromagnetic relations of the actual generator running process [1-6]. However, due to the limitations of the generator itself or the algorithm and the accuracy of the finite element software, the calculated current waveform always may not be the ideal sine alternating current and contains series of harmonics. Hence, the simulation generator current must be went through some certain process, only after this the simulation results can be integrated theory with practice and the generator performance can be analyzed systematically. It is well known that the Fourier transform is a common mathematical method of the harmonic and magnetic field analysis[7-11], but due to the algorithm limitation, Fourier transform cannot be carried out decomposition in both time and frequency domain at the same time. Hence, the application of Fourier transform can not fully express the transient characteristics of currents. Therefore, the wavelet transform method for the transient process analysis of current waveforms is considered to be used in this paper, and the accurate calculation of the transient negative-sequence component for the internal short circuit fault of the large generator can be realized. 
Wavelet analysis is an analytical method which can represent the local features of signal in time domain as well as in frequency domain. Therefore, wavelet transform is also known as the microscope of signal analysis [12,13]. Also because of this characteristic, wavelet transform overcomes Fourier transform's shortcomings, but it can not completely replace Fourier transform [14-16]. Hence, meshing the wavelet transform and Fourier transform will get good results.

Nowadays, the third generation nuclear power technology AP1000, which is leading the trend of nuclear power development all over the world, is already on the road to realization in China. The world's first AP1000 turbo-generator came off the assembly line by Harbin Power Plant Equipment Corporation in October 2012. However, there are lots of researches to do for AP1000 generator [17]. Hence, the wavelet transform application in transient component analysis for AP1000 Nuclear Turbo-generator is deeply discussed in this study.

\section{Fault Analysis of Large Generator Model}

This paper adopts AP1000 turbo-generator as the model, to carry out analysis and calculation of transient components based on wavelet transform. Considering the actual situation of the generator system, this section makes the assumptions that, the initial state is under no-load operation and three-phase fault occurs suddenly. Hence, in this condition, the main parameters and the interrelation of them have been analyzed, as shown in Figure 1.

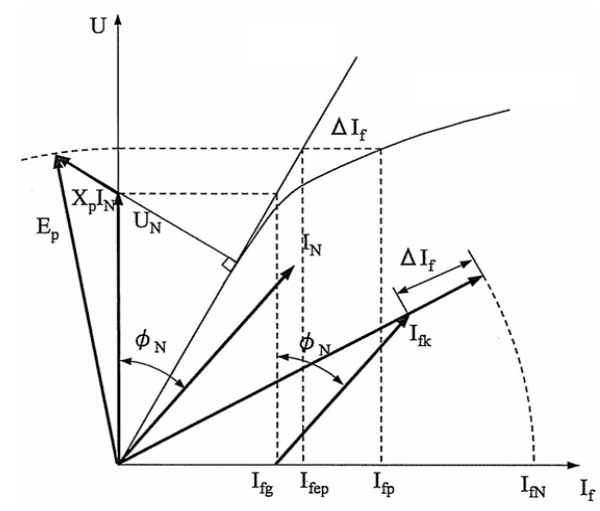

Figure 1. Main Parameters under No-load Operation

In quest of transient negative-sequence component's variety law, the changes of magnetic field in the generator system during the three-phase fault have been investigated in this section through the energy analysis. By the calculation of AP1000 turbo-generator, air-gap magnetic flux density can be presented in Figure 2. As well, the magnetic flux density distribution can be demonstrated in Figure 3.

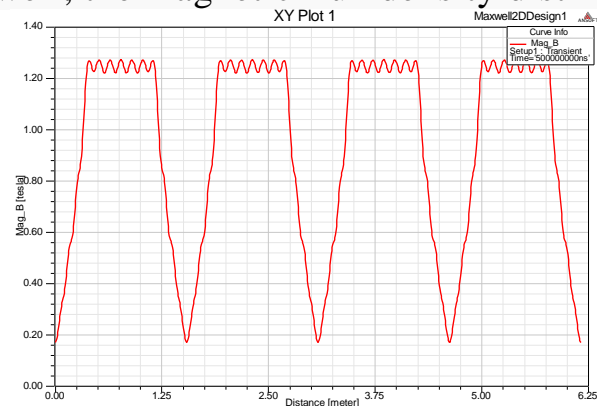

a. in no-load steady-state condition

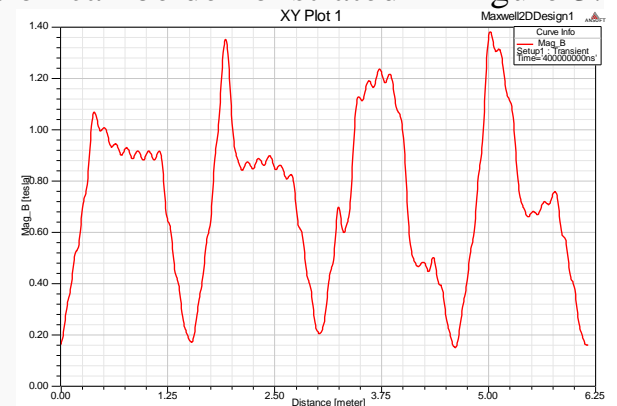

b. in three-phase fault

Figure 2. Air-gap Magnetic Flux Density 


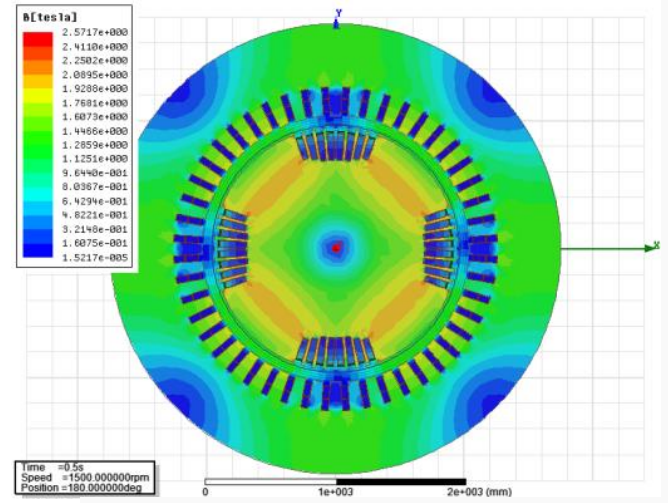

a. in no-load steady-state condition

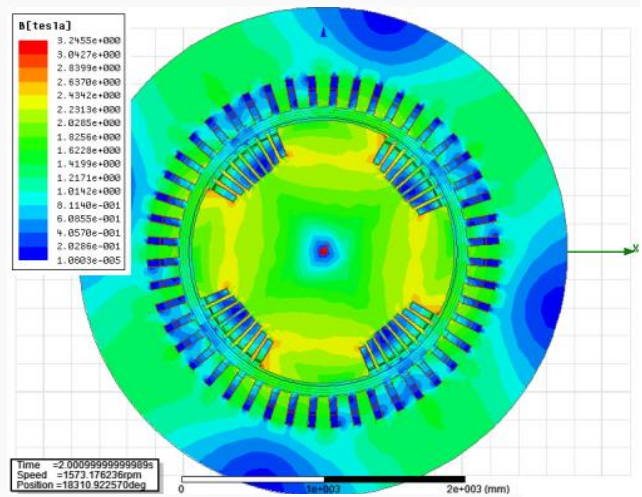

b. in three-phase fault

Figure 3. Magnetic Flux Density Distribution

From the results above, the pre-and post-fault changes of electromagnetic parameters are obvious by comparison. According to the magnetic flux density features before and after the fault moment, rotor heating is produced. Because the three-phase short circuit is symmetrical fault, the energy problems found in generator are among the worst it had been caused. Therefore, the no-load threephase short-circuit current of phase $A$ is taken as an example to illustrate the transient current waveform treatment process based on discrete wavelet transform.

\section{Application of Wavelet Transform in Transient Current Analysis}

In order to realize the usage of wavelet transform in computer calculations, the continuous wavelet transform signals must be discrete data.

$$
\left(W_{\psi} f\right)(a, b)=\left\langle f, \psi_{\mathrm{a}, \mathrm{b}}\right\rangle=\left|a_{0}\right|^{-\mathrm{m} / 2} \int_{-\infty}^{+\infty} f(t) \overline{\psi\left(a_{0}^{-\mathrm{m}} t-n b_{0}\right)} \mathrm{d} t
$$

Where: $a=a_{0}^{\mathrm{m}}, b=n b_{0} a_{0}^{\mathrm{m}}, m, n \in \mathrm{Z}$.

Hence, during the fault time, the three-phase current of phase A is expressed as:

$$
i_{\mathrm{A}}=-\left[\left(I_{\mathrm{m}}^{\prime \prime}-I_{\mathrm{m}}^{\prime}\right) e^{-\frac{t}{T_{\mathrm{d}}^{\prime \prime}}}+\left(I_{\mathrm{m}}^{\prime}-I_{\mathrm{m}}\right) e^{-\frac{t}{T_{\mathrm{d}}^{\prime}}}+I_{\mathrm{m}}\right] \cos \left(\omega t+\alpha_{0}\right)+I_{\mathrm{m}}^{\prime \prime} \cos \alpha_{0} e^{-\frac{t}{T_{\mathrm{d}}}}
$$

Where: $\alpha_{0}$ is the epoch angle;

$t$ is time;

$I_{m}$ is the steady-state current;

$I_{m}{ }^{\prime}$ is the initial amplitude of transient shortcircuit current;

$I_{m}{ }^{\prime \prime}$ is the initial amplitude of subtransient shortcircuit current;

$T_{d}{ }^{\prime \prime}$ is the direct axis subtransient time constant;

$T_{d}{ }^{\prime}$ is the direct axis transient time constant;

$T_{a}$ is the armature time constant.

When the epoch angle $\alpha_{0}=90^{\circ}$, the current waveforms are shown in Figure 4.

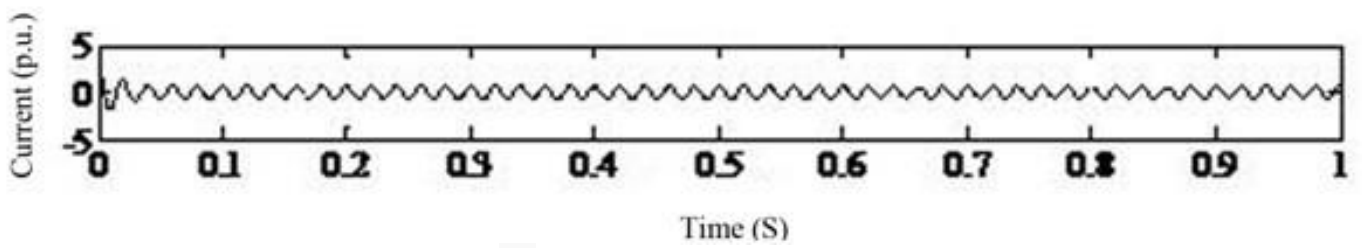

a. Transient component 


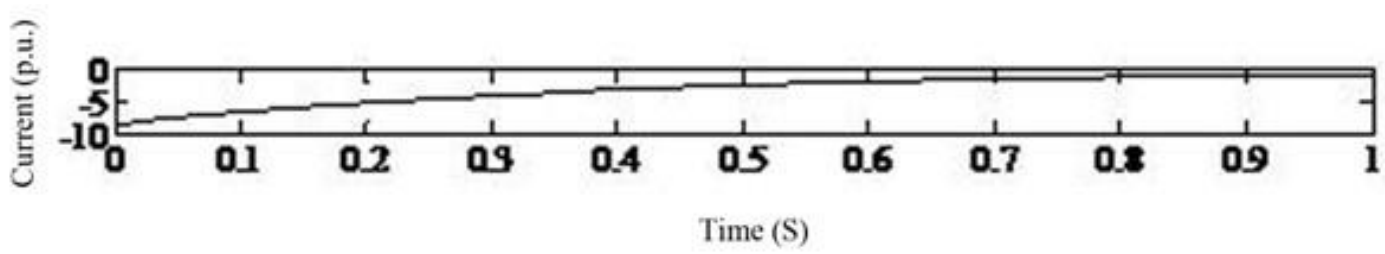

b. Non-periodic component

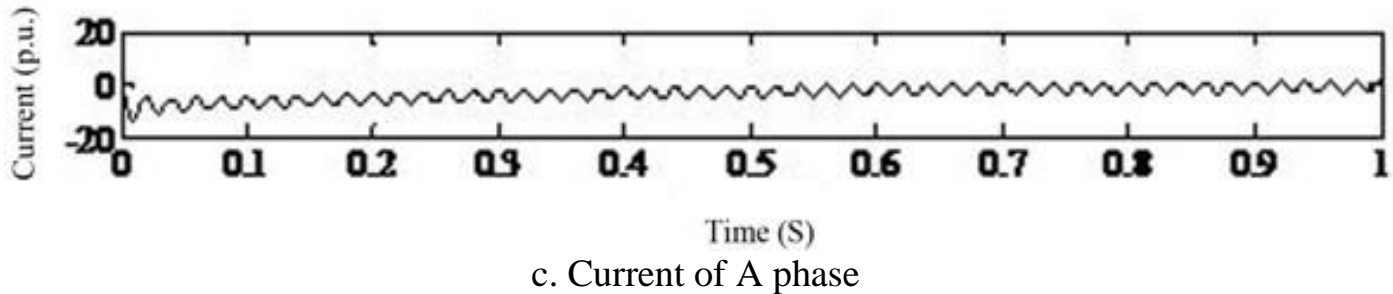

Figure 4. Current Waveform of Phase A

The transient current waveforms of the reconstruction and wavelet details by wavelet transform are shown in Figure 5.

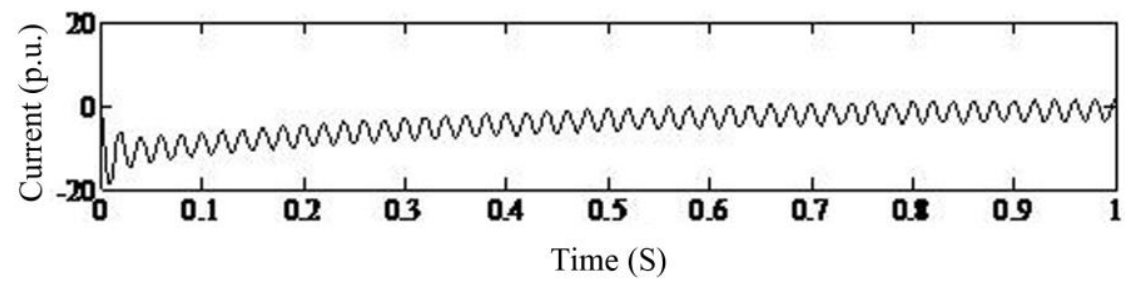

a. Reconstructed waveform of phase A

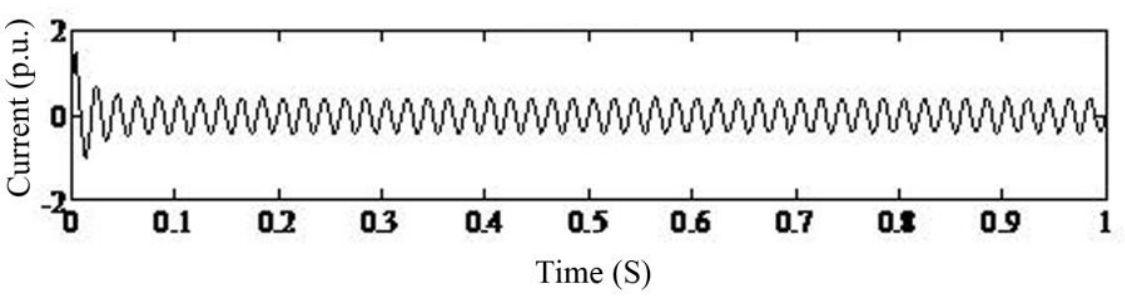

b. Wavelet detail

Figure 5. The Transformed Waveform of Phase A

From Figure 5 above, according to the reconstructed waveform of phase A and wavelet detail, it can be seen clearly that, the transformed current of phase A contains non-periodic component of primary current only, and wavelet detail has the periodic component of short-circuit current and harmonic components. Therefore, the transformed current of phase A contains steady current and non periodic component and the required parameters can be calculated at this time.

\section{Transient Parameters Calculations}

The armature winding internal fault is one of the common short circuits for generator system unites. In Figure 6 and 7, the armature winding structure of AP1000 generator is given, and the connection of armature windings is also got. Hence, this paper deals with 6 types of branch A2 and branch B1 short circuits in various fault positions, that are A21-B15, A21-B18, A23-B15, A23-B18, A24-B15 and A24-B18 short circuit. 


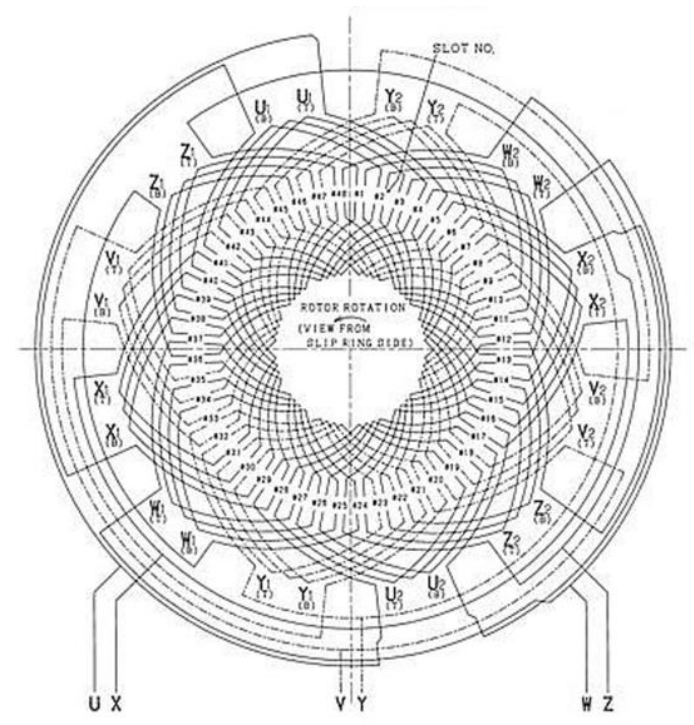

Figure 6. The Armature Windings of AP1000 Generator

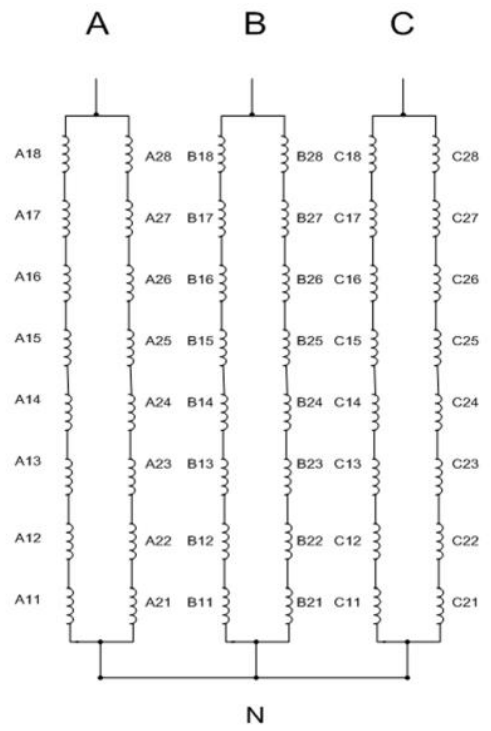

Figure 7. The Connection of Armature Windings

When the stator current waveforms are wavelet transformed, the results can be numerically analyzed. Therefore, the parameters can be obtained from the calculations of steady state short circuit currents and the transient negative-sequence capability can be also required.

According to the Formula (2), to calculate the transient-negative sequence components, the asymmetrical three-phase short-circuit current should be deeply researched and some transient parameters have to be obtained. From the results above, it has been come to a conclusion that when $\alpha_{0}=0^{\circ}$, the negative-sequence component gets the maximum value. Therefore, in order to calculate the transient negative-sequence component of AP1000 generator after the internal short circuit, the two important parameters, $T_{a}$ and $I_{m}$ ", need to be got at first.

The internal short circuit is unlike the external phase to phase short circuit, and values of $I_{m}$ " are smaller than the rated current value. According to the envelopes of the transient currents, the armature time constants of different internal short circuit 
faults are obtained. The two parameters corresponding to the different short circuit positions are shown in Figure 8.

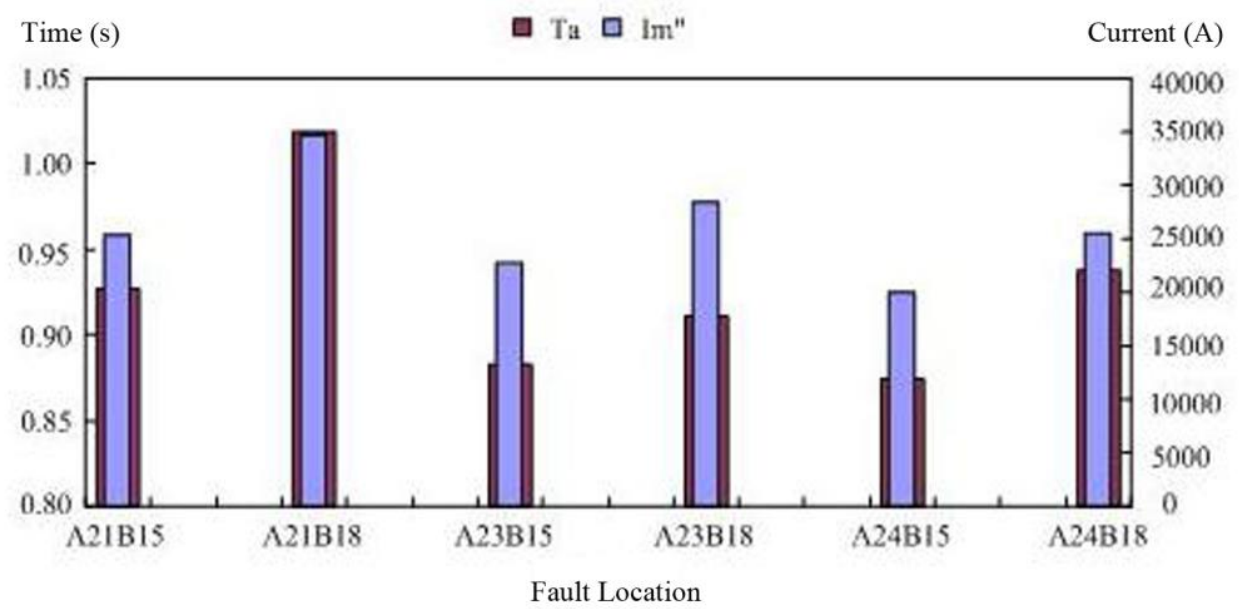

Figure 8. The Parameter Variations

During the internal phase fault of AP1000 generator, a part of armature winding is short-circuited in the internal fault. The short-circuited turns of phase A are few, and short-circuited turns of phase B are much more. All the short-circuited turns are not to participate in the exciting, so the internal phase fault is different from the external short circuit. Hence, in the internal short circuit, the asymmetric threephase windings lead to different values of three-phase currents. The calculation results of transient process data are got in Table 1. It can be seen clearly from Table 1 that there is no obvious difference in the data value of $T_{a}$ for the three-phase currents. In order to simplify the calculation, their respective average values of the three phases are used here for the non-periodic component computation.

Table 1. Parameters in Different Fault Location

\begin{tabular}{|c|c|c|c|c|}
\hline $\begin{array}{c}\text { Fault } \\
\text { location }\end{array}$ & Phase & $T_{\mathrm{a}}$ & $I_{\mathrm{m}}^{\prime \prime}$ & $\overline{T_{\mathrm{a}}}$ \\
\hline \multirow{3}{*}{ A21B15 } & A & 1.01 & 1.146 & \multirow{3}{*}{1.00} \\
\hline & B & 1.01 & 0.43 & \\
\hline & $\mathrm{C}$ & 0.99 & 1.18 & \\
\hline \multirow{3}{*}{ A21B18 } & A & 1.00 & 1.16 & \multirow{3}{*}{0.98} \\
\hline & B & 0.86 & 0.10 & \\
\hline & $\mathrm{C}$ & 1.09 & 1.12 & \\
\hline \multirow{3}{*}{ A23B15 } & A & 1.02 & 0.99 & \multirow{3}{*}{1.02} \\
\hline & B & 1.04 & 0.59 & \\
\hline & $\mathrm{C}$ & 1.02 & 1.25 & \\
\hline \multirow{3}{*}{ A23B18 } & A & 1.05 & 1.07 & \multirow{3}{*}{1.02} \\
\hline & B & 1.03 & 0.38 & \\
\hline & $\mathrm{C}$ & 0.99 & 1.22 & \\
\hline \multirow{3}{*}{ A24B15 } & A & 1.03 & 0.88 & \multirow{3}{*}{1.00} \\
\hline & B & 1.02 & 0.69 & \\
\hline & $\mathrm{C}$ & 0.96 & 1.28 & \\
\hline
\end{tabular}




\begin{tabular}{l|l|l|l|l}
\hline \multirow{2}{*}{$\mathrm{A} 24 \mathrm{~B} 18$} & $\mathrm{~A}$ & 1.06 & 1.00 & \multirow{2}{*}{1.04} \\
\cline { 2 - 4 } & $\mathrm{B}$ & 1.05 & 0.52 & \\
\cline { 2 - 4 } & $\mathrm{C}$ & 1.01 & 1.27 & \\
\hline
\end{tabular}

\section{Transient Negative-sequence Component Calculation}

In order to deeply discuss the negative-sequence ability, the non-periodic component should be seriously considered in the transient negative-sequence component calculation. In fact, the transient negative-sequence component contains two parts, the equivalent negative-sequence component of non-periodic component and the negative-sequence component of negative-sequence current.

Therefore, at this time the non-periodic component synthesis of three phases can be expressed as Formula (3).

$$
i_{\mathrm{r}}=\left(I_{\mathrm{mA}}^{\prime \prime}-\frac{1}{4} I_{\mathrm{mB}}^{\prime \prime}-\frac{1}{4} I_{\mathrm{mC}}^{\prime \prime}\right) e^{-\frac{t}{\overline{T_{\mathrm{a}}}}}
$$

The equivalent negative-sequence component of non-periodic component can be expressed as Formula (4).

$$
A_{2}=\frac{1}{4} \int_{0}^{t} i_{\mathrm{r}=}^{2} \mathrm{~d} t=\frac{1}{4}\left(I_{\mathrm{mA}}^{\prime \prime}-\frac{1}{4} I_{\mathrm{mB}}^{\prime \prime}-\frac{1}{4} I_{\mathrm{mC}}^{\prime \prime}\right)^{2} \frac{T_{\mathrm{a}}}{2}\left(1-e^{-\frac{2 t}{\overline{T_{\mathrm{a}}}}}\right)
$$

According to the revision of the national standard, in the calculation of $t=30 \mathrm{~s}$, the transient negative-sequence value of the internal phase fault must be not more than $5 \mathrm{~s}$, which is the requirement that the large generator should withstand. The calculation formula is improved by Formula (4), considering the non-periodic component effect produced by three-phase currents during the short circuit fault. The worst case is $\alpha_{0}=0^{\circ}$, and the transient-negative sequence components of vary short circuit faults have their maximum values. The A21-B15 fault is taken as an example, and the calculation results are list in Figure 9,10 and 11. It can be seen clearly that the equivalent transient negative-sequence component calculated by non-periodic component is a constant at about $1 \mathrm{~s}$, and the negative-sequence component produced by the negative-sequence current increases with time of the linear relationship.

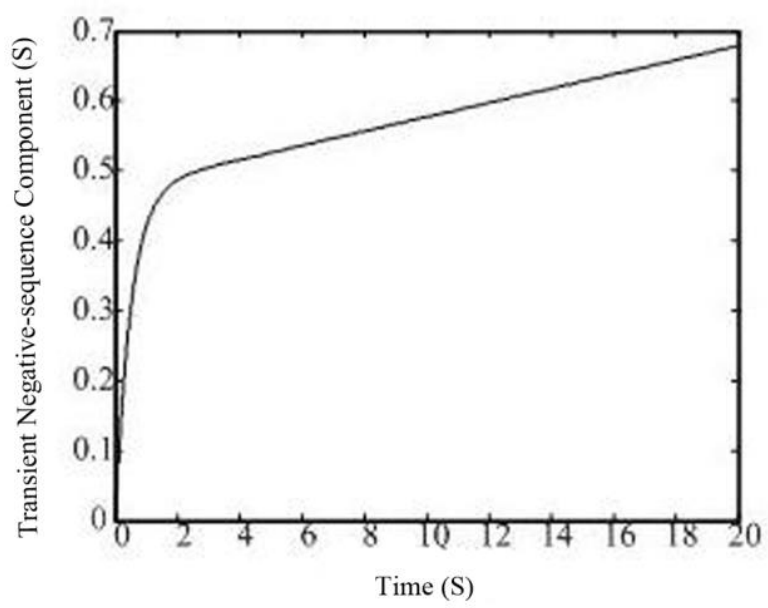

Figure 9. The Transient Negative-sequence Component of A21-B15 Fault 


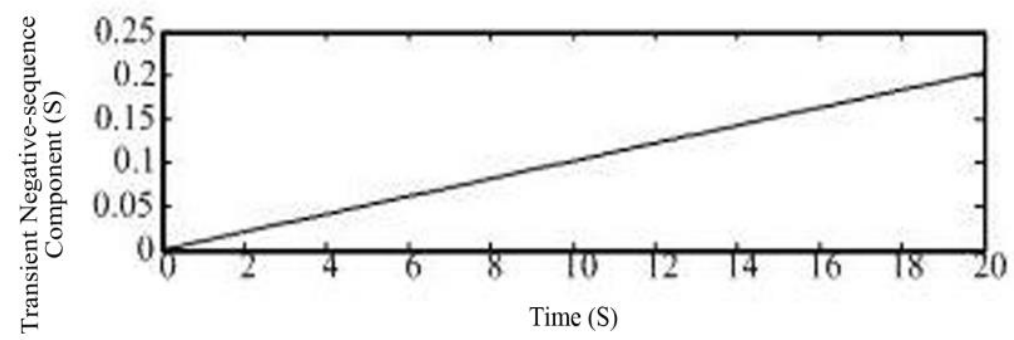

Figure 10. The Negative-sequence Component of Negative-sequence Current

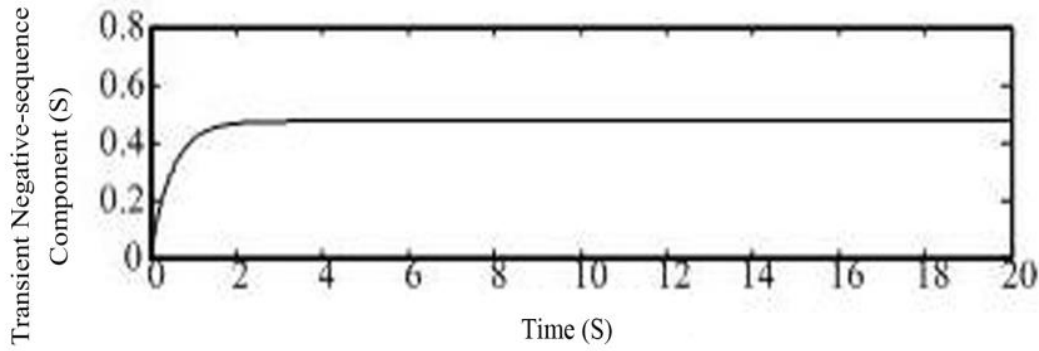

\section{Figure 11. The Equivalent Negative-sequence Component of Non-periodic Component}

According to Figure 9, 10 and 11, when the time is less than 1s, compared with the negative sequence current, the non-periodic component plays an important role on the rotor temperature rise. When the time is more than $1 \mathrm{~s}$, the non-periodic component part is stability and equals to a constant value. This paper deals with the faults between branch A2 and branch B1, and a part of windings the short circuited. Hence, the values of $I_{\mathrm{m}}^{\prime \prime}$ are small, which lead to the calculated results of transient negative-sequence are small. This paper carries out the calculations of the transient negative sequence component of various short circuit faults when $t=30 \mathrm{~s}$ and $60 \mathrm{~s}$, and the results are got as shown in Figure 12.

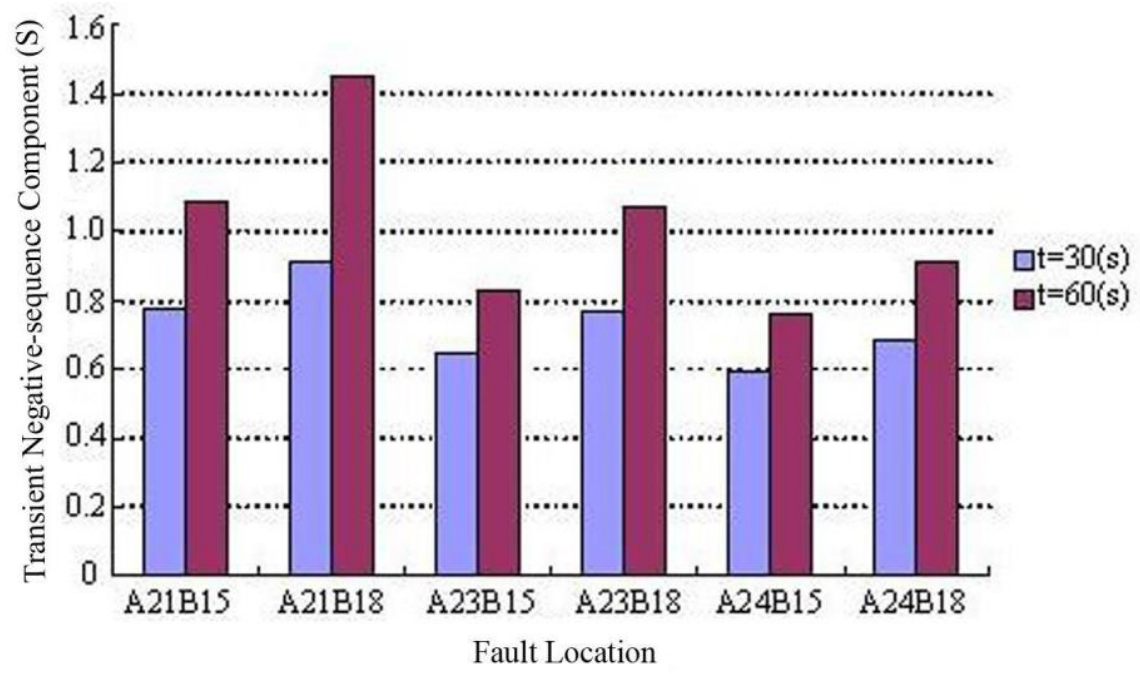

Figure 12. Transient Negative-sequence Components 
A part of the windings is short circuited during the internal short circuit. Although the asymmetric degree is high, the amplitude of the negative-sequence current is not large. Hence, the transient negative-sequence caused by the short circuit current does not exceed the transient negative-sequence capability of the large generator.

\section{Conclusions}

Due to the limitations of the Fourier transform, this paper puts forward the analysis method for the short circuit transient current using the wavelet transform. The non-periodic component and periodic component's fundamental part of the transient current are extracted, the high harmonics and the decreased periodic component are removed, and the current is obtained through finite element simulation which can be calculated according to the theoretical formula. Then the transient parameters of internal short circuit for the large generator are calculated according to the transformed current waveforms, the calculation formula is improved with the calculation of the transient negative-sequence, and calculations of transient negative-sequence components of the internal short circuits between branch B1 and branch A2 are carried out. After calculations, although the asymmetric degree is high, the magnitudes of the negative-sequence currents are not large, and the rotor transient heating does not exceed the generator's transient negative-sequence capability.

\section{Acknowledgements}

This work was supported by the National Major Scientific and Technological Special Project of China (No.2009ZX06004-013-04-01, Sub-project No.2012BAF03B01-X).

The authors appreciate the financial support from the National Major Scientific and Technological Special Project of the Chinese Government. And Harbin Electric Machinery Company Limited, Harbin, China, is also acknowledged for the technical support for this work.

\section{References}

[1] M Fujita, Y. Tokumasu and H. Tsuda, "Magnetic field analysis of stator core end region of large turbogenerators", Magnetics, vol. 36, (2000), 1850.

[2] M. V. K. Chari, S. H. Minnich and Z. J. Csendes, "Load Characteristics of Synchronous Generators by the Finite-Element Method", Power Apparatus and Systems, vol. 100, no. 1, (1981).

[3] T. Bach, D. Wohner and K. Takahashi, "Determining Negative Sequence Currents of Turbine Generator Rotors", Electrical Machines and Systems, (2009), pp. 1-6.

[4] J. Li, Y. Sun and G. Yang, "Calculation and analysis of 3D magnetic field for end region of large turbo generators", Electrical Machines and Systems, vol. 3, (2005), 2079.

[5] N. A. Demerdash and H. B. Hamilton, "A simplified approach to determination of saturated synchronous reactances of large turbogenerators under load", Power Apparatus and Systems, vol. 2, no. 560, (1976).

[6] B. Irwanto, K. Steigleder and O. Perros, "Large $60 \mathrm{~Hz}$ turbogenerators Mechanical design and improvements", Electric Machines and Drives Conference, (2009), pp. 471-476.

[7] Y. Wang, Y. Wang and H. Qiu, "Dynamic Design and Simulation Analysis of 1000MW Large TurboGenerator", Mechatronics and Automation, (2009), pp. 1650-1655.

[8] M. Pantelyat, G. Shulzhenko and G. Nikolaj, "Finite element analysis of electromagnetic field and losses in a turbogenerator rotor", Computational Electromagnetics, Albuquerque, (2006), pp. 1-2.

[9] H. Wang, S.-h. Li and W.-h. Dong, "Performance of Nuclear Power Plants Half-Speed Turbine", Power and Energy Engineering Conference", (2010), pp. 1-4.

[10] A. G. Jack and R. L. Stoll, "Negative-Sequence Currents and Losses in the Solid Rotor of a Turbogenerator", Transmission and Distribution, vol. 2, no. 53, (1980).

[11] L. Arjona and A. Marco, "Saturation effects on the Steady-state stability Limit of Turbine-Generators", IEEE T-EC, vol. 2, no. 133, (2004).

[12] A. C. Adewole and R. Tzoneva, "Fault Detection and Classification in a Distribution Network Integrated with Distributed Generators", IEEE Power Africa Conference and Exhibition, (2012). 
[13] H. Wang and G. Wang, "Application of Wavelet Transform and Fuzzy Theory for Turbo-Generator Fault Mode Classification", The Eighth International Conference on Electronic Measurement and Instruments, (2007), pp. 442-445.

[14] B.-j. Ge, W.-q. An, D.-j. Tao and P. Lin, "Simulation of the Temperature Field of Helium-colled Driving Motor Rotor End", JOURNAL OF HARBIN UNIVERSITY OF SCIENCE AND TECHNOLOGY, vol. 19, no. 4, (2014).

[15] H. Liangliang, S. Yuguang and Q. Ami, "Analysis on the Negative Sequence Impedance Directional Protection for Stator Internal Fault of Turbo Generator", Electrical Machines and Systems (2010), pp. 1421-1424.

[16] Sedlazeck, K. Richter and C. Strack, "Type Testing a 2000 MW Turbo Generator", Electric Machines and Drives Conference, (2009), pp. 465-470.

[17] B.-j. Ge, G. Wu and D.-h. Zhang, "Harmonic Analysis of AP1000 Large-capacity Turbo-generator Based on BP Neural Network", International Journal of Control and Automation, vol. 6, no. 163, (2013). 